Original Research Article

\title{
Effect of vitamin A supplementation in category-I Pulmonary Tuberculosis patients in a Medical College in India: a rapid assessment analysis
}

\author{
G. Sujatha ${ }^{1}$, M. Dhanasekaran ${ }^{1}$, Syed Shuja Qadri*², S. Jeevithan²
}

\begin{abstract}
${ }^{1}$ Department of Pharmacology, Government Mohan Kumaramangalam Medical College and Hospital, Salem, Tamil Nadu, India ${ }^{2}$ Department of Community Medicine, Karpagam Faculty of Medical Sciences and Research, Coimbatore, Tamil Nadu, India
\end{abstract}

Received: 15 November 2016 Accepted: 01 December 2016

\section{*Correspondence to: \\ Dr. Syed Shuja Qadri, \\ Email: ssaqadri@yahoo.com}

Copyright: (C) the author(s), publisher and licensee Medip Academy. This is an openaccess article distributed under the terms of the Creative Commons Attribution NonCommercial License, which permits unrestricted noncommercial use, distribution, and reproduction in any medium, provided the original work is properly cited.

\begin{abstract}
Background: Tuberculosis is one of the major health problems affecting the global population causing immense morbidity and mortality. Studies have shown that a good antioxidant status of the body has immune protective role against tuberculosis and may be associated with a decreased risk of the disease and slower rate of progression. Objective of the study was planned to evaluate the beneficial effects of Vitamin A as add on therapy to the standard drug therapy in patients with sputum positive pulmonary tuberculosis.

Methods: The study was done in a Tuberculosis clinic, Department of Internal Medicine, Stanley Medical College for duration of 6 months. All the newly diagnosed sputum positive pulmonary tuberculosis patients (18-55 years) attending the outpatient were taken for the study purpose. A Phase III, prospective, open, two arm parallel group, outpatient, randomized, active controlled study was done.
\end{abstract}

Results: After two weeks of therapy, the number of patients with negative sputum smear was higher in the study group than the control group. Vitamin A supplementation resulted in an earlier elimination of tubercle bacilli from the sputum.

Conclusions: This study shows that vitamin A as add on therapy to the existing standard therapy improves the clinical response and decreases the disease activity to a greater extent than with routine standard therapy alone.

Keywords: Anti-oxidants, Tuberculosis, Vitamin A

\section{INTRODUCTION}

Tuberculosis is one of the major health problems affecting the global population causing immense morbidity and mortality. In India, tuberculosis kills more adults in the reproductive age group (15-54years) than any other infectious disease causing distress to families and communities. ${ }^{1}$

Chemotherapy with multi drug regimens is highly effective in the treatment of tuberculosis. Despite this, in
India it has been found that about 2.4 percent of new patients have multi drug resistant tuberculosis. ${ }^{2}$

Epidemiological and observational studies suggest that increase oxidative stress and defective antioxidant status may be associated with an increased risk of tuberculosis and faster disease progression. The generation of oxygen free radicals by activated macrophages is responsible for many of the pathophysiological changes associated with tuberculosis. This has fostered the view that antioxidants can have a significant role in the clinical outcome of tuberculosis patients. Studies have shown that vitamin A, 
as an antioxidant also has immunoprotective role against tuberculosis.

Hence, there is a need to clarify whether supplementation of vitamin A with anti-tuberculosis drugs could increase the efficacy of treatment in patients with sputum positive pulmonary tuberculosis.

\section{METHODS}

The study was carried out in the Tuberculosis clinic, Department of Internal Medicine, Stanley Medical College for a period of 6 months. All the newly diagnosed sputum positive pulmonary tuberculosis patients (18-55 years) attending the outpatient were taken for the study purpose.

\section{Study design}

A randomized, active controlled study was done. It was a Phase III, prospective, open, two arm parallel group design.

Sample size was about totally 100 patients (50 patients in each group).

\section{Inclusion criteria}

1. Newly diagnosed sputum positive pulmonary tuberculosis patients

2. Age group 18-55 years

3. Both sexes

\section{Exclusion criteria}

1. Extra pulmonary tuberculosis patients

2. Sputum smear negative pulmonary tuberculosis patients

3. Pregnant and lactating women

4. Patients with HIV co-infection

5. Patients with associated chronic medical/ surgical illness

6. Smokers

7. Alcoholics

\section{Strategy}

Patients who attended the OPD of tuberculosis clinic were explained in detail about the study procedure, purpose and its benefits. They were assured of utmost confidentiality. Written informed consent was obtained from the patients willing to participate in the study, in the prescribed format in the regional language.

\section{Screening and recruitment}

Patients who had given the informed consent for participation in the study were screened by medical history, physical examination, systemic examination, sputum smear examination, chest X-ray, blood samples for hematological and biochemical analysis. Finally 100 patients who fulfilled the inclusion criteria were recruited for the study purpose.

\section{Randomization}

Among the 100 patients, all the odd number patients were given vitamin $\mathrm{A}$ in addition to the regular medications [study group] and even number patients were given only the regular medications (control group).

\section{Control group and study group}

Isoniazid $600 \mathrm{mg}+$ Rifampicin $600 \mathrm{mg}+$ Pyrazinamide $2000 \mathrm{mg}+$ Ethambutol $1600 \mathrm{mg}$ three times a week on alternate days for two months. In addition to the above drugs, vitamin A 25000 IU capsule once a week for two months to the study group subjects. All the patients were instructed to come weekly to collect the medication and were advised to take their medicines regularly. The necessity for compliance to the regimen was explained. Any adverse events experienced by the patients were to be reported at the next visit.

\section{Assessment and follow up}

The patients were asked to come to the clinic every week to deliver their sputum. Sputum was examined by direct microscopy after Ziehl- Neelson staining. The time when the first of three weeks consecutive sputum smears of good quality was negative was noted. If all the sputum samples were not delivered or if the sputum was not of adequate quality, patients were excluded from analysis of sputum conversion time. After two months of active drug therapy, both the control and study groups were followed up for a period of four months.

\section{Ethical consideration}

Approval of ethical committee of our institution was sought before conducting the study. Informed \& written consent from all the participants was taken. Confidentiality was maintained at all times during the course of the study. There was no financial burden to the participants.

\section{Data analysis}

The data thus obtained was analyzed using SPSS software (version 20). Appropriate statistical methods (Chi-square, t-test and Logistic regression) were applied as per requirement. $P$ value $\leq 0.05$ was considered significant.

\section{RESULTS}

An epidemiological study was conducted to find out the Effect of Vitamin A supplementation in Category-I Pulmonary Tuberculosis patients in a Medical College in India. The study was carried for a period of six months. 
Figure 1 depicts the general profile of the study population. Out of the 126 patients screened, 100 patients who fulfilled the inclusion criteria were recruited for the study. They were randomized into control and study groups. There were 9 drop outs ( 5 from the control group and 4 from the study group). None of the drop outs were due to adverse effects. Finally 91 patients (45 from the control group and 46 from the study group) completed the study. It was further found that out that in study group $63 \%$ were males and $37 \%$ females were as in control group, $53.3 \%$ were males and $46.7 \%$ females respectively. However there was no statistical association between the gender of the patients and the study groups in which they were allocated $(\mathrm{p}=0.34)$.

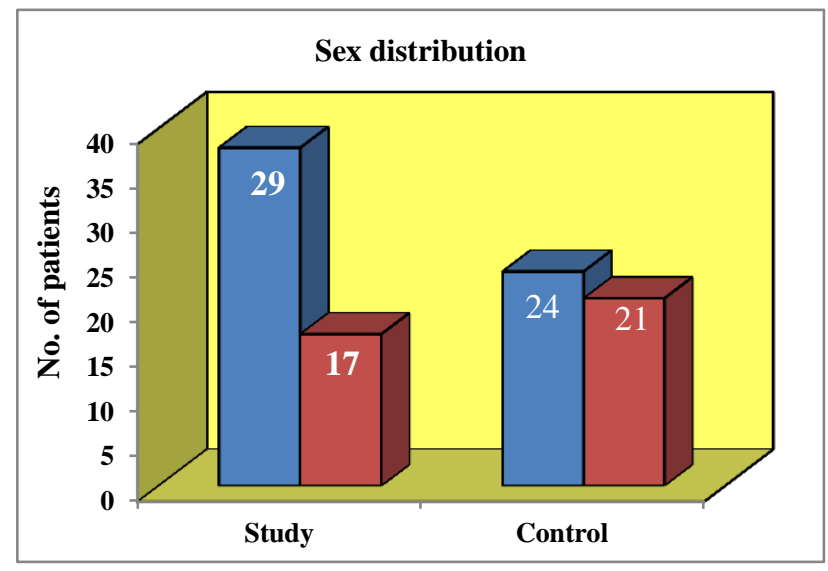

Figure 1: Depicts the sex wise distribution of the study population.

Figure 2 depicts the age wise distribution of the study population. It was found that maximum of the patients in the study belonged to the age group of 20-50 years with high prevalence among males. . It was further observed that in the study group mean age of the patients was 37.85 with SD 14.989 whereas in control group it was 33.76 with SD 11.888. However no statistical association could be found between age of the patients and the study groups in which they were allocated $(\mathrm{p}=0.15)$.

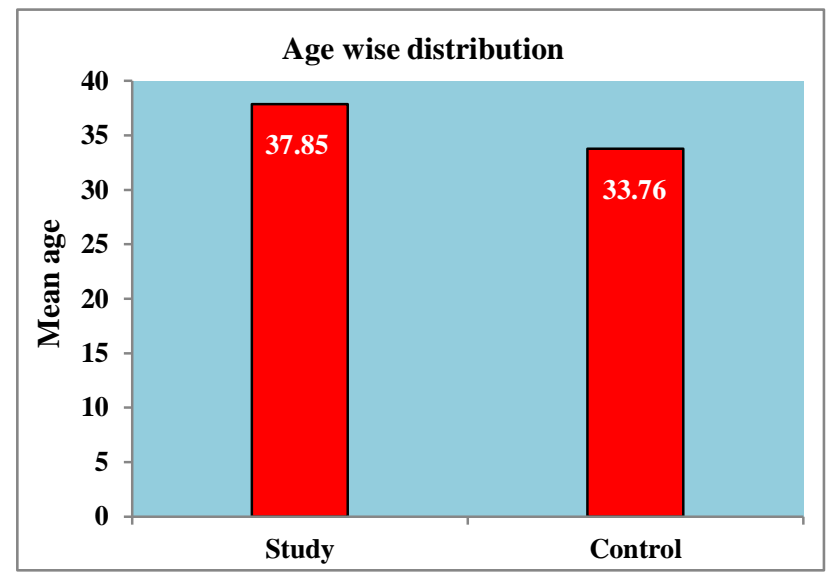

Figure 2: Depicts the age wise distribution of the study population.
Table 1 reveals the sputum conversion time between the study group and the control group from Ist to the VIIIth week. It was observed that there was no statistically significant difference between the groups at the baseline. However there was a statistically significant difference in the study group when compared with the control group at the end of second week which was maintained till the end of seventh week $(\mathrm{p}<0.05)$.

Table 3: Depicts the sputum conversion time.

\begin{tabular}{|llllll|}
\hline & \multicolumn{2}{l}{ Group } & & & Independent \\
& \multicolumn{2}{l}{ Control } & Study & & t-test \\
& Mean & SD & Mean & SD & \\
\hline Week I & 2.11 & 0.80 & 2.20 & 0.86 & $\mathrm{t}=0.48 \mathrm{P}=0.62$ \\
\hline Week II & 1.91 & 0.70 & 1.52 & 0.84 & $\mathrm{t}=2.40 \mathrm{P}=0.02$ \\
\hline Week III & 1.24 & 0.71 & 0.74 & 0.83 & $\mathrm{t}=3.12 \mathrm{P}=0.002$ \\
\hline Week IV & 0.58 & 0.69 & 0.28 & 0.54 & $\mathrm{t}=2.26 \mathrm{P}=0.03$ \\
\hline Week V & 0.29 & 0.59 & 0.09 & 0.28 & $\mathrm{t}=2.09 \mathrm{P}=0.04$ \\
\hline Week VI & 0.13 & 0.34 & 0.02 & 0.15 & $\mathrm{t}=2.02 \mathrm{P}=0.05$ \\
\hline $\begin{array}{l}\text { Week } \\
\text { VII }\end{array}$ & 0.09 & 0.29 & 0.00 & 0.00 & $\mathrm{t}=2.09 \mathrm{P}=0.04$ \\
\hline $\begin{array}{l}\text { Week } \\
\text { VIII }\end{array}$ & 0.04 & 0.21 & 0.00 & 0.00 & $\mathrm{t}=0.46 \mathrm{P}=0.64$ \\
\hline
\end{tabular}

\section{DISCUSSION}

This 8 week randomized, active controlled prospective study examined the beneficial effects of vitamin A supplementation at the dose of 25000 IU once weekly as an add on therapy with regular anti- tuberculosis treatment in patients with category I pulmonary tuberculosis. Sputum smear examination for the presence of tubercle bacilli was done at weekly intervals during the study period to monitor the patient's progress towards cure.

From the results of this study it was evident that after 2 weeks of the therapy, the number of patients with negative sputum smear was higher in the study group than the control group. This was maintained up to 6 weeks of study. Vitamin A supplementation resulted in an earlier elimination of tubercle bacilli from the sputum. This was in correlation with the results of Elvina Karyadi et al, who showed that vitamin $A$ and zinc supplementation improved the efficacy of tuberculosis treatment and resulted in earlier sputum conversion. ${ }^{3}$ This could be attributed to the influence of vitamin $\mathrm{A}$ on the immune system. Pulmonary tissue is rich in nuclear retinoic acid receptors, and vitamin A is directly utilized by them. ${ }^{4}$ A study had reported that retinoic acid inhibit the multiplication of virulent tubercle bacilli in cultured human macrophages. ${ }^{5}$ Another study had shown increased bacterial binding to respiratory epithelial cells in vitamin A deficiency. ${ }^{6}$

In our study, vitamin A supplementation would have inhibited the multiplication of tubercle bacilli and thus resulted in earlier sputum conversion. At the community 
level, faster sputum conversion would reduce the risk of tuberculosis transmission.

\section{CONCLUSION}

In conclusion, this study shows that vitamin $\mathrm{A}$ as add on therapy to the existing standard therapy improves the clinical response and decreases the disease activity to a greater extent than with routine standard drug therapy alone. In view of its low cost, safety and efficacy it would be useful to add vitamin A supplementation along with current anti- tuberculosis treatment regimens, so that it may be possible to reduce the dose of the antituberculosis drugs or to introduce a shorter regimen. This could lead to a better compliance, higher cure rate and cost effective anti-tuberculosis treatment.

Funding: No funding sources

Conflict of interest: None declared

Ethical approval: The study was approved by the Institutional Ethics Committee

\section{REFERENCES}

1. WHO. Global Tuberculosis Control, Surveillance, Planning, WHO report 2006.

2. Park K. Preventive and Social Medicine; $19^{\text {th }}$ Edition; 169.

3. Karyadi E, West CE, Schultink W, Nelwan RHH, Gross R, Amin Z, et al. Vitamin A and Zinc supplementation in persons with tuberculosis in Indonesia: effects on clinical response and nutritional status. Am J Clin Nutr. 2002;75:720-7.

4. Chytil F. The lungs and vitamin A, Am J Physiology. 1992;262;L517-27.

5. Crowle AJ, Ross EJ. Inhibition by retinoic acid of multiplication of virulent tubercle bacilli in cultured human macrophages. Infect Immun. 1989;57:840-4.

6. Chandra RK. Increased bacterial binding to respiratory epithelial cells in vitamin A deficiency. Br Med J (Clin Res Ed). 1988;297:834-35.

Cite this article as: Sujatha G, Dhanasekaran M, Qadri SS, Jeevithan S. Effect of vitamin A supplementation in category-I Pulmonary

Tuberculosis patients in a Medical College in India: a rapid assessment analysis. Int $\mathrm{J}$ Basic Clin Pharmacol 2017;6:66-9. 